Europe's Journal of Psychology 2/2010, pp. 65-84

www.ejop.org

\title{
Why do some people ruminate more or less than others? The role of Emotional Intelligence ability
}

\section{Tiziana Lanciano}

University of Bari

\section{Antonietta Curci}

University of Bari

\section{Edvige Zatton}

University of Bari

\begin{abstract}
Emotional Intelligence (EI) has been defined as an ability to evaluate, perceive and express emotions, use emotions to facilitate thought, analyse and understand emotions, and manage and regulate emotions. The emotional elaboration ability is considered a crucial skill for El, because of its role on the individual well-being. Individuals differ in adopting more or less successful emotion elaboration strategies. Among the many strategies, mental rumination is conceptualized as being characterized by persistent thoughts which intrude into the consciousness in a repetitive way. As a consequence, individual differences in mental rumination may be related to differences in El abilities. The aim of the present study was to investigate the relationship between mental rumination and El abilities. More specifically, Study $1(N=150)$ investigated this association with respect to the emotional valence of an emotionally inducing event (positive vs. negative). Study $2(N=88)$ explored the impact of El on the mental rumination processes both immediately after an emotional event and over time. Results, jointly considered, supported the idea that people with a higher level of managing emotions ability had reduced frequency of mental rumination, independent of the valence of the emotional event and retention delay.
\end{abstract}

Keywords: mental rumination, intrusive thoughts, emotional elaboration, emotional processing, emotional intelligence 
Emotional Intelligence (EI) is a relatively new domain of psychological investigation, having recently met considerable attention and interest. The concept of El was first proposed by Salovey and Mayer (1990) who defined it as a set of abilities dealing with emotions and the processing of emotional information. Theoretical and empirical research has led to the development of several models of El, providing different frameworks for conceptualising and measuring El. These models can be grouped into three main theoretical approaches: a) mixed models that conceptualised $\mathrm{El}$ as both personality traits and abilities related to emotional and social knowledge (e.g., Bar-On, 1997); b) competence models which include a large set of socio-emotional competencies, defined as learned capabilities le.g., Goleman, 2001); c) models of El as cognitive-emotional ability (Mayer \& Salovey, 1997).

Mayer and Salovey (1990, p. 189) formally described El as the cognitive-emotional ability "to monitor one's own and others' feelings, to discriminate among them, and to use this information to guide one's thinking and action". This definition was later reviewed and El was conceptualized in four distinct abilities, the so-called branches of the model (Mayer \& Salovey, 1997). The first branch - perceiving emotions - is the ability to recognize emotions in faces, pictures, voices, and cultural artefacts. It also includes the ability to identify one's own emotions. Perceiving emotions may represent the most basic aspect of $\mathrm{El}$, as it makes all other processing of emotional information possible. The second branch - using emotions - is the ability to use emotions in order to facilitate several cognitive activities, such as thinking, memory, and problem solving. The third branch of El - understanding emotions - is the ability to comprehend emotional language and to appreciate complicated relationships among emotions (e.g. knowing the transition from one emotion to another). Furthermore, it includes the ability to recognize and describe how emotions evolve over time. The fourth branch - managing emotions - consists of the ability to regulate emotions in both ourselves and in others, in order to decrease negative ones and maintain positive ones. The four branches form a hierarchy, with emotional perception at the bottom and management of emotions at the top.

Studies on El have shown that these human capacities involve emotional information processing (Austin, 2005; Salovey et al., 1995). Emotional processing ability refers to "a process whereby emotional disturbances are absorbed, and decline to the extent that other experiences and behaviour can proceed without disruption" (Rachman, 1980, p. 51). Although the elaboration of emotional information is a universal phenomenon and occurs in everyday life, it always takes place in specific contexts of the individual's life. Individuals differ in their ability to elaborate emotions, by choosing more or less successful and adaptive processes (Mayer \& Salovey, 1997; 
Salovey \& Mayer, 1990). Mental rumination is generally considered as an emotion elaboration strategy aimed to cognitively integrate or resolve the emotional experiences (Horowitz, 1997; Janoff-Bulman, 1992). It is characterized by intrusive, repetitive, unwanted thoughts, and images that interrupt ongoing activities and are difficult to control (Rachman, 1981). The literature on the rumination phenomenon agrees on the disruptive effect and intrusiveness of persistent rumination with respect to ordinary life activities. Intrusive and ruminative thoughts may be positive or negative, they may appear in a number of ways - images, impulses, verbal thoughts or recurring memories - and they can be aversive and disturbing when the individual is performing other everyday activities (Rachman \& Hodgson, 1980).

A question regarding the rumination phenomenon which remains open is: Why is it that following an emotional event, there are people who have more (or less) ruminative thoughts than others? Individual differences in frequency of ruminative thoughts have traditionally been addresses to the emotional impact of the triggering experience. However, the emotional impact alone is not able to sufficiently explain these differences (Lanciano, Bianco, Curci, \& Cozzoli Poli, 2009; Luminet, Zech, Rimé, \& Wagner, 2000; Rimé, Finkenaver, Luminet, Zech, \& Philippot, 1998). Given this, differences in mental rumination could be related to differences in emotional elaboration ability. In turns, these differences in emotional processing may be correlated to differences in El abilities. Indeed, according to some studies (Ramos, Fernandez-Berrocal, \& Extremera, 2007), successful processing of intrusive and ruminative thoughts depends, in part, on the level of perceived emotional intelligence. Additionally, perceived emotional intelligence contributes to reduced tendencies towards maladaptive emotion regulation strategies such as ruminative responses (Rude \& McCarthy, 2003; Salovey et al., 1995).

Overview and aim of the studies

The two current studies have mainly focused on mental rumination as a strategy to elaborate and manage an emotional experience. Additionally, the two studies aimed to determine whether, and to what extent, individual differences in mental rumination could be related to different levels of El ability.

Both present studies are based on Salovey and Mayer's El model (1990), focused on emotion-related abilities which can be assessed through performance-based tests. The most recently developed ability measure of El is the Mayer-Salovey-Caruso Emotional Intelligence Test (MSCEIT; Mayer, Salovey, \& Caruso, 2002), which measures the four core emotional abilities, i.e. Perceiving emotions, Using emotions, Understanding emotions, and Managing emotions. Moreover, in the present studies, 
mental rumination is considered as the long-term persistence of unwanted thoughts, experienced by individuals in the hours, days, and years following the emotional experience (Rimé, 1995).

All El branches of the Mayer, Salovey and Caruso's model (2002) - Perceiving, Using, Understanding, Managing - were expected to be negatively associated with the frequency of ruminative thoughts. More specifically, managing emotions was expected to have the highest negative correlation with mental rumination. Indeed this ability would help people to better process and elaborate the emotionally arousing information, enabling a greater recovery and decline in intrusive thoughts (Gohm, Baumann, \& Sniezek, 2001; Ramos et al.,2007; Salovey et al. 1995).

In Study 1, following an emotional experience (positive vs. negative), intrusive and ruminative thoughts were expected to be elicited. The frequency of these ruminative thoughts was expected to be lower for individuals with high levels of El, more specifically with higher levels of the Managing emotions ability (Ramos et al., 2007). In the present study, mental rumination has been conceptualized as a troubling process when individuals are performing other everyday activities. According to this point of view, both positive and negative ruminative thoughts could be disturbing and need to be reduced (Rachman \& Hodgson, 1980). As a consequence, higher levels of El abilities were expected to correspond to fewer intrusive thoughts (both positive and negative).

Study 2 was designed to investigate the role of El on mental rumination immediately following a negative emotional experience, and after a long time. People try to avoid disturbing ruminative thoughts over time. As a consequence, the frequency of ruminative thoughts was expected to be reduced for individuals with high levels of El abilities, not only immediately after the event but also over time (Ramos et al., 2007).

Study 1

Method

Design

Study 1 adopted a one-way factor design with the Emotional valence of the event (Positive vs. Negative) as a between-subjects factor. Dependent variables were measures of El branches, Emotion feeling states following an emotional experience, and Mental rumination. 
Participants

The sample was composed of 150 undergraduate students from the University of Bari, Italy (79.3\% women; $M$ age $=21.07 ; S D=4.24)$, randomly assigned to one out of the two Emotional valence of the event conditions ( $50.7 \%$ Negative condition).

Measures

Emotional intelligence test. Measures of El used in the present study corresponded to the Italian version of the original MSCEIT (Curci \& D'Amico, 2010; D'Amico \& Curci, 2010; Mayer Salovey Caruso Emotional Intelligence Test; Mayer et al., 2002). The test measures individuals' performance on tasks and ability to solve emotional problems. It provides a total emotional intelligence score as well as four branch (sub-scale) scores: Perceiving, Using, Understanding, and Managing emotion. Each branch comprised scores of two sections described in more detail below. The four branches can also be conceptually distinguished in terms of experiential (perception, facilitation) or strategic (understanding, management) aspects. Consensus scoring ${ }^{1}$ is the preferred method for assessing El abilities as it provides a solution to the problem of determining what constitutes a correct answer (Mayer et al., 2002). The consensus approach is based on what the majority of the respondents regard as correct and has been shown to be more effective than the target method (i.e. what target identifies as expressed or felt). Participants' scores reflect the degree of fit between their responses and those of the norm for this sample.

Perceiving Emotions. Two sections A (Face) and E (Images) measure emotion in four faces, three landscapes, and three abstract pictures. In the faces task the participant reports on the emotional content of each face rating the degree of happiness, fear, surprise, disgust and excitement on a five-point scale 1 = "no emotion"; 5 = "extreme amount of emotion"). On the landscape task, participants" reactions to the pictures are rated in terms of happiness, fear, anger, disgust. The three abstract tasks are rated on sadness, fear, anger, surprise, disgust on a similar five-point scale ( 1 = "no emotion"; 5 = "extreme amount of emotion").

Using Emotions. Section B (Facilitation) assesses participants' knowledge of how different moods can be effective for certain kinds of problem solving. A choice of three options is provided on a five-point scale. Section $F$ (Sensation) involves comparing how different emotions can be related to other sensations, on a fivepoint scale (1 = "not alike"; 5 = "very much alike").

${ }^{1}$ Consensus scoring was computed based on the US normative sample, since the validation of the scoring system of the Italian version of MSCEIT is presently in progress (Curci \& D'Amico, 2010; D'Amico \& Curci, 2010). 
Understanding Emotions. Section G (Blends) measures a person's ability to label emotions and group emotional terms together. Using a multi choice format participants try to match a set of emotions to another single emotion. Section C (Changes) assesses knowledge of how emotions combine and change.

Managing Emotions. Section H (Social Management) is concerned with emotions in relationships. Participants are asked to evaluate the effectiveness of different actions in achieving a specified outcome that involves other people. Section D (Emotion Management) is concerned with emotion management in the individual and other people. Five different scenarios are presented which describe a person with a goal of changing or maintaining a feeling. Each of a list of four different actions is evaluated in terms of effectiveness.

Emotional feeling states. Participants were asked to rate, on an 11-point scale $10=$ "not all"; 10 = "very much"), the level of Emotional Intensity felt immediately after the chosen emotional event. In addition, twelve 7-point scales (0 = "not at all"; $6=$ "very much"), assessed the degree to which participants felt basic emotions: a) interest, b) joy, c) surprise, d) sadness, e) anger, f) disgust, g) fear, h) shame, i) guilt, I) happiness, m) anxiety, and n) contempt (Differential Emotion Scale, DES; Izard, Dougherty, Bloxom, \& Kotsch, 1974). Scores on item b) and I) of the Emotional feeling state section were averaged to get the Positive emotions index (Cronbach's alpha $=.97$ ). Additionally, scores on items d), e), f), g), h), i), m), and n) of the Emotional feeling state section were averaged to get the Negative emotions index (Cronbach's alpha $=.90)$.

Rumination. Mental rumination was assessed by retrospective self-report measures, since the study focused on the rumination considered as an emotion elaboration strategy following an emotional experience. Participants were asked to assess, on two 6-point scales ( 0 = "never"; 5 = "very often"): a) how often they had thought about the past emotional event, and b) how often images, thoughts or memories of the event had tended to spontaneously come back to their consciousness. These items were the same used by Rimé and colleagues in their studies (1991; Rimé, Noel \& Philippot, 1991). Item scores of this section were averaged to get the index of Mental rumination ranging from 0 to 5 (Cronbach's alpha $=.91$ ).

Procedure

Students were recruited during a psychology class and requested to individually fill in the Italian version of MSCEIT (Curci \& D'Amico, 2010; D'Amico \& Curci, 2010; Mayer et al., 2002). Immediately after, participants were randomly assigned to one of two 
emotional valence conditions: In the positive event condition participants were asked to read a list of 20 positive events and to choose one of them occurring within the last three months; participants in the negative event condition were asked to read a list of 20 negative events and to choose one of them occurring within the last three months. Then, each participant filled in a questionnaire concerning the emotions felt following the selected emotional event, and the consequent ruminative processes.

Results

Descriptive analyses of El measures

Table 1 presents the basic statistics for the four El branches. The results are comparable to most recently published data (Kafetsios, 2004; Mayer et al., 2002).

Table 1: Zero-order correlation coefficients among El branches (Study 1)

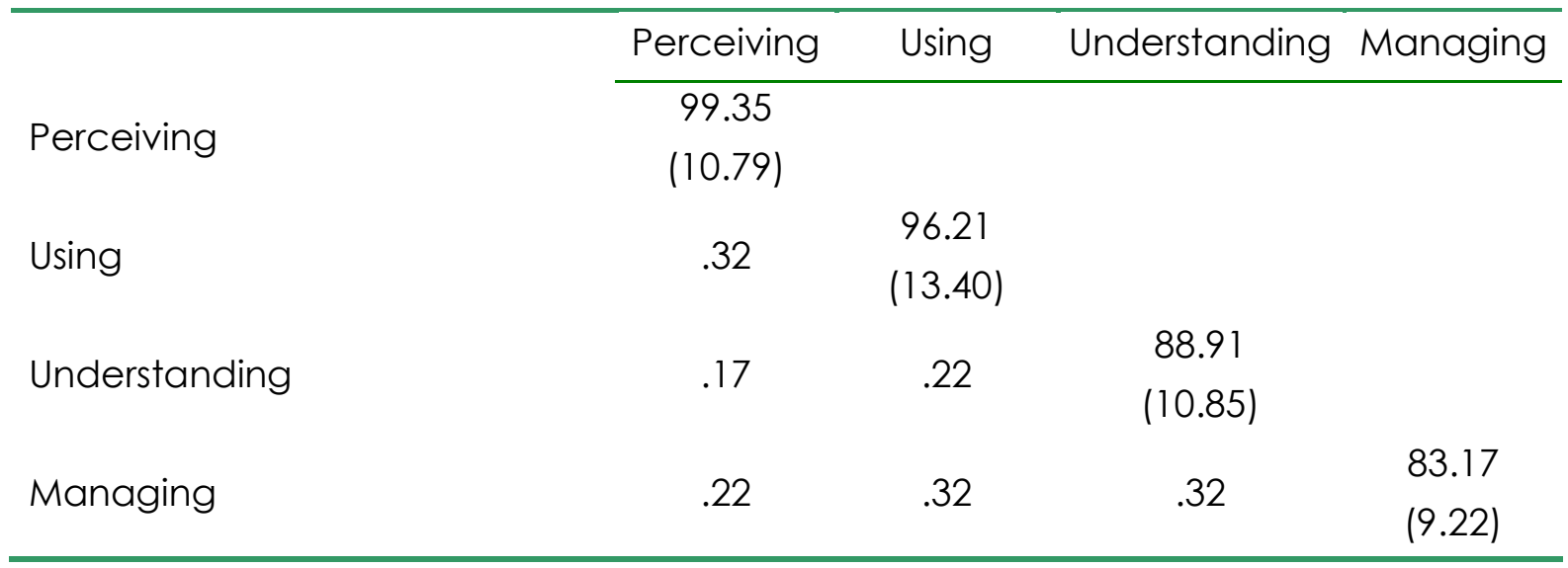

Note: Ms and SDs are provided in diagonal. All reported correlations were significant for $p<.01$.

The effect of Emotional valence of the event

A t-test was run on the measures of Emotional feeling states (Emotional Intensity, Surprise, Negative emotions, and Positive emotions) and Rumination with the Emotional valence of the event (Positive vs. Negative) as the between subject factor. Compared to the positive event condition, negative experiences were evaluated as more emotionally intense, and gave rise to a higher level of negative emotions. Additionally, in the positive event condition, participants seemed to feel more positive emotions. No significant differences were found for valence in the ratings of surprise and the frequency of ruminative thoughts (see Table 2). 
Table 2: Effects of the Emotional valence of the event on the measures of Emotion feeling states and Rumination (Study 1)

\begin{tabular}{lccc}
\hline & $M$ Negative & $M$ positive & t-test \\
& $(S D)$ & $($ df) & (SD) \\
\cline { 2 - 4 } Emotional Intensity & 7.16 & 4.23 & $6.16^{*}$ \\
Surprise & $(2.27)$ & $(3.44)$ & -1.85 \\
Negative emotions & 2.87 & 3.39 & \\
& $(1.65)$ & $(1.80)$ & $14.96^{*}$ \\
Positive emotions & 3.2 & .77 & $-21.17^{*}$ \\
& $(1.11)$ & $(.88)$ & 1.78 \\
Mental rumination & .44 & 4.78 & $(1.49)$ \\
\hline
\end{tabular}

Note: $* p<.001, d f=148$

Correlation analyses

The correlations between El branches and Rumination for the positive and negative event conditions are presented in Table 3. Generally, Rumination had consistent negative correlations with Perceiving, Understanding, and Managing emotion abilities. For the negative emotional condition, the Managing emotions ability appeared to be negatively associated with the frequency of ruminative thoughts. On the other hand, for the positive emotional condition, results showed a significant negative correlation between the frequency of ruminative thoughts and the skills of Understanding and Managing emotions. This indicates that the higher the levels of these El abilities, the less people tend to ruminate about their emotional experiences.

Table 3: Zero-order correlation coefficients between El branches and Rumination for the emotional valence of the event (Study 1)

\begin{tabular}{lccc}
\hline & \multicolumn{3}{c}{ Mental Rumination } \\
\cline { 2 - 4 } & $\begin{array}{c}\text { Negative event } \\
\text { condition }\end{array}$ & $\begin{array}{c}\text { Positive event } \\
\text { condition }\end{array}$ & Total sample \\
\cline { 2 - 4 } Perceiving & -.22 & -.18 & $-.20^{*}$ \\
Using & -.09 & -.12 & -.012 \\
Understanding & -.14 & $-.27^{*}$ & $-.21^{* *}$ \\
Managing & $-.57^{* *}$ & $-.72^{* *}$ & $-.66^{* *}$ \\
\hline
\end{tabular}

Note: ${ }^{* *} p<.001 ; * p<.05$ 
Regression analyses

Two stepwise multiple regression analyses were run as a stronger test of association between Rumination and El branch abilities, by taking into account the role of the Emotional valence of the event (Table 4). For both regressions, the dependent variable was the index of Rumination. The independent variables of the first block were the El branch scores; in the second block the ratings of Emotional Intensity of the event were included; in the third block the ratings of Surprise; in the last block the indices of Negative and Positive emotions.

The present results showed that Rumination following negative emotional events appeared to be positively predicted by the ratings of Emotional Intensity and negatively predicted by the ability of Managing emotions. For the positive event condition, the only significant predictor of Rumination was the Managing skill. To sum up, the evaluation of Emotional Intensity given by participants to their negative emotional experience seemed to enhance their consequent mental rumination; on the other hand, the ability to manage emotions would decrease the frequency of ruminative thoughts for both negative and positive emotional events.

Table 4: Multiple regressions of El branches on Rumination (Study 1)

\begin{tabular}{|c|c|c|c|c|}
\hline & \multicolumn{4}{|c|}{ Mental rumination } \\
\hline & \multicolumn{2}{|c|}{ Negative event } & \multicolumn{2}{|c|}{ Positive event } \\
\hline & $\begin{array}{c}R^{2}=.35^{* *}, \\
\left(F_{2,75}=\right. \\
21.04, p< \\
.001)\end{array}$ & $\beta$ & $\begin{array}{c}R^{2}=.51^{* *}, \\
\left(F_{1,73}=\right. \\
78.19, p< \\
.001)\end{array}$ & $\beta$ \\
\hline \multicolumn{5}{|l|}{$1^{\text {st }}$ block } \\
\hline Perceiving & & -.15 & & .02 \\
\hline Using & & 1.13 & & .06 \\
\hline Understanding & & .06 & & -.08 \\
\hline Managing & & $-.60 * *$ & & $-.72^{* *}$ \\
\hline \multicolumn{5}{|l|}{$2^{\text {nd }}$ block } \\
\hline Emotional Intensity & & $.20^{*}$ & & .06 \\
\hline \multicolumn{5}{|l|}{$3^{\text {rd }}$ block } \\
\hline Surprise & & -.04 & & .15 \\
\hline \multicolumn{5}{|l|}{$4^{\text {th }}$ block } \\
\hline Negative emotions & & .01 & & .06 \\
\hline Positive Emotions & & .03 & & -.01 \\
\hline
\end{tabular}

Note: ${ }^{*} p<.05 ; * * p<.001$ 
Discussion

Study 1 investigated the process of mental rumination following an emotional experience (negative or positive). A major strength of Study 1 is the fact that it considers the effect of the valence of the emotional experience on the relationship between rumination and El. Results showed that, compared to positive events, negative experiences were evaluated as more emotionally intense, and gave rise to a higher level of negative emotions. No significant differences between the positive and the negative emotional events were found for the frequency of ruminative thoughts. These results are in line with Rimé et al.'s studies (1991), showing that more than $95 \%$ of their participants spontaneously ruminated about their emotional experiences. Consistently, in neither of the two studies reported in Rimé et al. (1991) were significant differences found between positive and negative experiences.

Nevertheless, the main aim of the present study was to investigate the association between mental rumination and El abilities. More specifically, the ability to manage emotions was expected to have a significant role in reducing mental rumination. People able to elaborate emotional information were more able to manage emotional incoming information, obtaining a greater recovery from their experience, and a decline in the associated intrusive thoughts (Gohm, Baumann, \& Sniezek, 2001; Ramos et al., 2007; Salovey et al, 1995).

Generally, the current findings theoretically and empirically supported the link between mental rumination and the managing emotions ability. Results showed that mental rumination appeared to be negatively influenced by the ability to manage personal and others' emotions. These results may be understood by considering that mental rumination is conceptualized as intrusive thoughts which may be positive or negative, on the basis of the emotional valence of the triggering experience. As a consequence, independent of the emotional content of these thoughts, people try to suppress them to avoid further rumination (Erskine, Kvavilashvili, \& Kornbrot, 2007). It follows that people able to accurately manage and regulate emotions (El ability) appeared to have less intrusive thoughts. 


\section{Study 2}

Method

\section{Design}

Study 2 used a repeated-measure design with the Retention Interval (Few hours vs. Five months after the event; i.e., Time 1 vs. Time 2) as a within-subjects factor. Dependent variables were measures of El branches, Emotional feeling states, and Rumination.

Participants

The sample was composed of 88 undergraduate students from the University of Bari, Italy (93.2\% women; Mage $=19.31 ; S D=1.20)$.

\section{Measures and Procedures}

Measures of El branches, Emotional feeling state (Emotional Intensity, Surprise, Negative emotions, and Positive emotions), and Rumination were the same used in the Study 1. Concerning the ratings of Rumination, two measures were collected, respectively at Time 1 and Time 2 .

The Diary. Students were recruited during a psychology seminar and requested to individually fill in the Italian version of the MSCEIT (Curci \& D'Amico, 2010; D'Amico \& Curci, 2010; Mayer et al., 2002) in a laboratory room. One week after this task, during a psychology class, all participants were requested to keep a diary for seven days as soon as an emotional event had happened in their life in the days following the delivery of the diary. Immediately after these instructions, a state of emotional stress and alarm was induced in the class: An accomplice suddenly came into the room, shouting nonsensically and moving around the class for a few minutes provoking panic among the students. As soon as he went out, the majority of the students $198 \%$ of the original sample) agreed to write about this event in their diaries. This situation was planned in order to have a standard (negative) stimulus event to which all students were asked to respond.

In the days following the event, before going to bed, participants described the event and answered the same set of questions proposed in Study 1 (rumination assessed at Time 1). When participants handed back their diary, they were fully debriefed. After five months, participants were contacted and instructed to answer 
again some questions concerning the emotional event, such as the frequency of ruminative thoughts (rumination assessed at Time 2$)^{2}$.

Results

Descriptive analyses

Descriptive analyses on the measures of Emotional feeling state, and Rumination supported the efficacy of the manipulation of the emotional event: Participants evaluated the event as emotionally intense and surprising. Additionally, they reported high levels of negative emotions and a high frequency of ruminative thoughts and images following the event (Figure 1).

Concerning the effect of Retention interval on the frequency of Mental rumination, results showed a significant decrease of ruminative thoughts over time (Mrumination_timel $=2.81, S D=.78 ; M_{\text {rumination_time2 }}=1.28, S D=.68 ; t=15.85, p<.001$ ).

Table 5 presents the basic statistics for the four El branches. The Perceiving emotions ability appeared to positively correlate with the abilities of Using and Managing emotions; moreover the Understanding emotions ability seemed to be positively correlated with the Managing emotions ability.

Table 5: Zero-order correlation coefficients among El branches (Study 2)

\begin{tabular}{|c|c|c|c|c|}
\hline & Perceiving & Using & Understanding & Managing \\
\hline \multirow[t]{2}{*}{ Perceiving } & 99.12 & & & \\
\hline & $(10.21)$ & & & \\
\hline \multirow[t]{2}{*}{ Using } & & 97.98 & & \\
\hline & $.32^{*}$ & (13.42) & & \\
\hline \multirow[t]{2}{*}{ Understanding } & & & 89.73 & \\
\hline & .16 & -.03 & (7.90) & \\
\hline \multirow[t]{2}{*}{ Managing } & & & & 82.70 \\
\hline & $.33^{*}$ & .16 & $.20^{*}$ & (7.12) \\
\hline
\end{tabular}

Note: Ms and SDs are provided in diagonal; ${ }^{*} p<.01$.

\footnotetext{
${ }^{2}$ The measure of rumination at Time 1 refers to the ratings collected at the first day of the event (and of the diary); the measure of rumination at Time 2 refers to the ratings collected after five months.
} 
Figure 1: Scores of Emotional feeling states, and Rumination (Study 2)

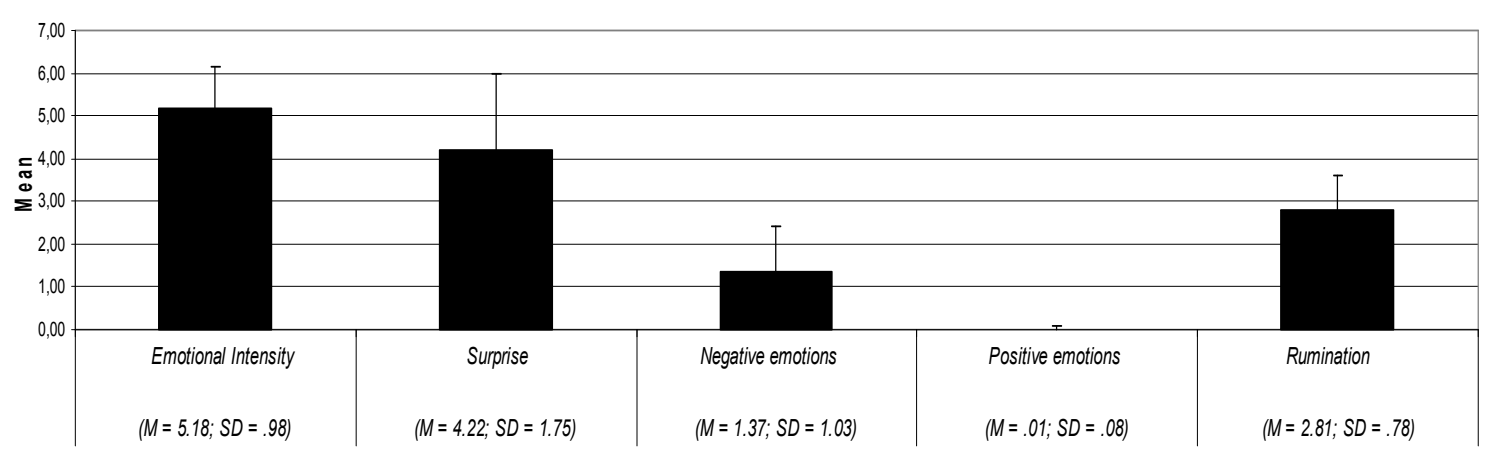

Correlation analyses

Table 6 shows the correlations between El branch scores and Rumination assessed at both Time 1 and Time 2. Results revealed that Rumination immediately following the event appeared to negatively correlate with the ability of Perceiving, Understanding, and Managing emotions. In addition, Rumination assessed at Time 2 seemed to be negatively associated with the ability of Using and Managing emotions.

Table 6: Zero-order correlation coefficients between El branches and Rumination assessed at Time 1 and Time 2 (Study 2)

\begin{tabular}{lccc}
\hline & \multicolumn{2}{c}{ Mental rumination } \\
\cline { 2 - 3 } & Time 1 & Time 2 \\
\cline { 2 - 3 } Perceiving & $-.41^{* *}$ & -.71 \\
Using & -.18 & $-.22^{*}$ \\
Understanding & $-.23^{*}$ & -.20 \\
Managing & $-.80^{* *}$ & $-.30^{* *}$ \\
\hline
\end{tabular}

Note: ${ }^{*} p<.05 ;{ }^{* *} p<.001$

Regression analyses

Two multiple hierarchical regression analyses were conducted as a stronger test of association between El branch abilities and Rumination assessed both at Time 1 and Time 2 (Table 7). For both regressions, the independent variables of the first block were the El branch scores; in the second block the ratings of Emotional Intensity of the event were included; in the third block the ratings of Surprise; in the last block the indices of Negative and Positive emotions. The dependent variables were Rumination at Time 1 and Rumination at Time 2, respectively. 
Concerning Rumination at Time 1, results showed that ruminative thoughts were negatively predicted by the ability to Manage and Perceive emotions, and positively predicted by the ratings of Importance and Emotional Intensity of the event. In contrast, for Rumination assessed at Time 2, findings supported the significant role of the emotional Management ability, and the level of intensity of positive emotions felt after the event.

Table 7: Multiple regressions of El branches on Rumination (Study 2)

\begin{tabular}{|c|c|c|c|c|}
\hline & \multicolumn{4}{|c|}{ Mental rumination } \\
\hline & \multicolumn{2}{|c|}{ Time 1} & \multicolumn{2}{|c|}{ Time 2} \\
\hline & $\begin{array}{c}R^{2}=.68^{* *}, \\
\left(F_{3,87}=\right. \\
63.06, p< \\
.001)\end{array}$ & $\beta$ & $\begin{array}{c}R^{2}=.12^{*} \\
\left(F_{2,86}=6.71\right. \\
p<.01)\end{array}$ & $\beta$ \\
\hline \multicolumn{5}{|l|}{$1^{\text {st }}$ block } \\
\hline Perceiving & & $-.17^{*}$ & & -.08 \\
\hline Using & & -.04 & & -.16 \\
\hline Understanding & & -.06 & & -.13 \\
\hline Managing & & $-.76^{* *}$ & & $-.30 *$ \\
\hline \multicolumn{5}{|l|}{$2^{\text {nd }}$ block } \\
\hline Emotional Intensity & & $.18^{*}$ & & -.15 \\
\hline \multicolumn{5}{|l|}{ 3rd block } \\
\hline Surprise & & -.02 & & -.19 \\
\hline \multicolumn{5}{|l|}{$4^{\text {th }}$ block } \\
\hline Negative emotions & & .06 & & .18 \\
\hline Positive Emotions & & -.05 & & $.21^{*}$ \\
\hline
\end{tabular}

Note: ${ }^{*} p<.05 ;{ }^{* *} p<.001$

\section{Discussion}

Study 2 aimed to test the association between El ability and rumination following a negative emotional event. The major strength of this study was that it investigated mental rumination in a controlled context, since the triggering emotional event was simulated with the help of an accomplice. Additionally, the present study aimed to investigate if El ability influences the ruminative processes not only immediately after the event, but also over time. 
First, results supported the efficacy of the experimental manipulation of the emotional event: Following the (simulated) event, people evaluated their experience as emotionally intense, reported high levels of negative emotions, and developed ruminative thoughts and images. The frequency of mental rumination appeared to decline over time. Concerning the main aim of the present study, as for Study 1 , the current results supported a consistent association between the El abilities and the frequency of mental rumination: Higher skills of perceiving and managing emotions seemed to be associated with a decrease of ruminative thoughts, immediately after a negative emotional experience.

People experience a variety of emotional events throughout their life, and use different strategies to manage these situations. Mental rumination is an emotional elaboration strategy which might persist for hours, days, and months following the triggering emotional event (Rimé et al., 1992). As a consequence, the role of the $\mathrm{El}$ abilities becomes crucial not only immediately after the emotional event, but also over time, when individuals are asked to deal with the long-term effects of the emotional experience.

\section{General discussion}

El was defined as an ability to evaluate, perceive and express emotions, use emotions to facilitate thought, analyse and understand emotions, and manage and regulate emotions (Mayer \& Salovey, 1997). Strategies of emotional elaboration are thought to strongly interact with El abilities because of their great role for the individual well-being and social relationships. People differ in adopting more or less adaptive emotion elaboration strategies, on the basis of the contextual demands and personal goals. Among the several strategies people use, mental rumination is generally considered a strategy characterized by intrusive, repetitive, unwanted thoughts, and images that interrupt ongoing activities, and are difficult to control (Rachman, 1981).

One of the most recent controversies about the rumination phenomenon is related to individual differences on rumination. The emotional impact of the eliciting event is not sufficient to explain these differences (Lanciano, et al., 2009; Luminet et al., 2000; Rimé et al., 1998). A possible factor accounting for these differences could be different emotion elaboration strategies, which, in turn, are strictly related to the El abilities. As a consequence, individual differences on the frequency of ruminative thoughts may be associated to different levels of El skills. There is growing evidence that people with high levels of El abilities process and assimilate more appropriately the emotions experienced, dealing better with emotional issues, for example, using 
more adaptive responses such as reducing ruminative processes (FernandezBerrocal \& Ramos, 2002; Ramos et al., 2007).

The two current studies aimed to theoretically and empirically investigate this link between the mental rumination and the El abilities. More specifically, Study 1 explored if this relationship varied as a function of the emotional valence of the event (positive vs. negative), and study 2 aimed to investigate the role of El on the mental rumination not only immediately after the event, but also over time.

Results from both studies, jointly considered, supported the association between mental rumination and managing emotion ability: people with a higher level of emotion elaboration ability had a reduced frequency of mental rumination, independent of the valence of the emotional inducing event (negative vs. positive), or the retention interval (immediately and after a long time). Taken together, the findings showed that people reporting a high ability of managing emotions might process and assimilate more appropriately the emotions they experienced, such as by reducing or eliminating ruminative thoughts (Fernandez-Berrocal \& Ramos, 2002).

A noteworthy aspect of this research work is the exploration of the role of emotion valence in the relationship between rumination and El. Mental rumination is characterized by intrusive thoughts which may be positive or negative on the basis of the valence of the emotional experience. People try to avoid both these disturbing thoughts, and, as a consequence - following an emotional event - people who are emotionally intelligent are also able to deal with these thoughts, by managing them. The current studies also took advantage of the existence of MSCEIT as an ability-measure of emotional intelligence, rarely adopted in similar correlational studies (Bastian, Burns, \& Nettelbeck, 2005; Gohm, Corser, \& Dalsky, 2005; Kafetsios, 2004).

The present findings give an important theoretical contribution to the literature on the elaboration of emotional information, and, also, to El literature. They show that, in order to better and more clearly understand emotional elaboration strategies, it is worth investigating individual differences on these strategies (i.e. individual differences on mental rumination). These differences could be related to different levels of El abilities which individuals use to elaborate and process incoming emotional information. As a consequence, if a link between $\mathrm{El}$ and emotion elaboration is supposed, improving and developing El abilities - through training may be a valuable tool which people could use to better deal with one's own and other's emotions (Tugade \& Fredrickson, 2002; 2007). Additionally, further studies 
focused on the investigation of individual differences on emotion elaboration strategies should consider the key role of El.

Despite these interesting findings, the present research has several limitations. First, as with all work concerning complex and multifarious phenomena, an important limit concerns the causal inferences that can be made on the basis of the correlational studies. Indeed, some other factors might be hypothesized to influence both mental rumination and El, by mediating on the link between them, such as the individual coping style (Campbell \& Ntobedzi, 2007) or the ruminative response style (NolenHoeksema, 1991). Second, an investigation with a sample prevalently composed by female undergraduate students might raise some doubts on the generalisation of results, and on the ecological validity of the research. Further studies might consider also these other individual features and investigate the influence of the relationship between Mental Rumination and El on the individual's psychological well-being. In addition a more representative sample may be involved in further research, to allow researchers to get a broader generalization of their results.

\section{References}

Austin, E.J. (2005). Emotional intelligence and emotional information processing. Personality and Individual Differences 39, 403-414

Bar-On, R. (1997). BarOn emotional quotient inventory: technical manual. Toronto: MultiHealth Systems.

Bastian, V.A., Burns, N.R., \& Nettelbeck, T. (2005). Emotional intelligence predicts life skills, but not as well as personality and cognitive abilities. Personality and Individual Differences, 39, $1135-1145$.

Campbell, A. \& Ntobedzi, A. (2007). Emotional Intelligence, Coping and Psychological Distress: A Partial Least Squares Approach to Developing a Predictive Modeling. Electronic Journal of Applied Psychology, 3, 39-54.

Christianson, S.-A., \& Lotus, E. F. (1991 ). Remembering emotional events: The fate of detailed information. Emotion \& Cognition, 5, 81-108.

Curci, A. \& D'Amico, A. (2010). Taratura italiana del Mayer-Salovey-Caruso Emotional Intelligence Test (MSCEIT). Firenze: O.S. 
D'Amico, A. \& Curci, A. (2010). Traduzione ed adattamento italiano del Mayer-SaloveyCaruso Emotional Intelligence Test (MSCEIT). Firenze: O.S.

Erskine, J. A. K., Kvavilashvili, L., \& Kornbrot, D. E. (2007). The predictors of thought suppression in young and old adults: Effects of rumination, anxiety, and other variables. Personality and Individual Differences, 42, 1047-1057.

Fernández-Berrocal, P. \& Ramos, N. (2002). Corazones Inteligentes. Barcelona: Kairos.

Gohm, C.L., Corser, G.C., \& Dalsky, D.J. (2005). Emotional intelligence under stress: Useful, unnecessary, or irrelevant? Personality and Individual Differences, 39, 1017-1028.

Gohm, C. L., Baumann, M. R., \& Sniezek, J. A. (2001). Personality in extreme situations: Thinking (or not) under acute stress. Journal of Research in Personality, 35, 388-399.

Goleman, D. (2001). Emotional Intelligence: Issues in paradigm building. In C. Cherniss \& D. Goleman (Eds.), The Emotionally Intelligent Workplace, (pp. 13-26), Jossey-Bass: San Francisco.

Kafetsios, K. (2004). Attachment and emotional intelligence abilities across the life course. Personality and Individual Differences, 37, 129-145.

Horowitz, M. J. (1979). Psychological response to serious life events. In V. Hamilton \& D. M. Warburton (Eds.), Human stress and cognition: An information processing approach (pp. 235-263). Chichester, UK: Wiley.

Janoff-Bulman, R. (1992). Shattered assumptions: Towards a new psychology of trauma. New York: Free Press.

Izard, C. E., Dougherty, F. E., Bloxom, B. M. \& Kotsch, N. E. (1974). The Differential Emotion Scale: A method of measuring the meaning of subjective experience of discrete emotions. Nashville: Vanderbilt University, Department of Psychology.

Lanciano, T., Bianco, A., Curci, A., \& Cozzoli Poli, G. (2009). Le differenze individuali nella ruminazione mentale di esperienze emozionali (tr. it. Individual Differences on mental Rumination of Emotional Experiences). Giornale Italiano di Psicologia, 3, 509-533.

Luminet, O., Zech, E., Rimé, B., \& Wagner, H. (2000). Predicting cognitive and social consequences of emotional episodes: The contribution of emotional intensity, the Five Factor model, and alexithymia. Journal of Research in Personality, 34, 471-497.

Mayer, J. D. \& Salovey, P. (1997). What is emotional intelligence? In P. Salovey \& D. J. Sluyter (Eds.), Emotional development and emotional intelligence (pp. 3-31). New York: Basic Books. 
Mayer, J. D., Salovey, P., \& Caruso, D. R. (2000). Selecting a measure of emotional intelligence: the case for ability scales. In R. Bar-On \& J. D. A. Parker (Eds.), The handbook of emotional intelligence. San Francisco: Jossey-Bass.

Mayer, J.D., Salovey, P., Caruso, D.R. (2002). Mayer-Salovey-Caruso emotional intelligence test (MSCEIT) user's manual. Toronto, Ontario, Canada: MHS Publisher.

Nolen-Hoeksema, S. (1991). Responses to depression and their effects on the duration of depressive episodes. Journal of Abnormal Psychology, 100, 569-582.

Rachman, S. (1981). The Primacy of Affect: Some Theo-retical Implications. Behavior Research and Therapy, 19, 279-290.

Rachman, S. (1980). Emotional processing. Behavior Research and Therapy, 18, 51-60.

Rachman, S., \& Hodgson, R. (1980). Obsessions and compulsions. Englewood Cliffs, NJ: Prentice Hall.

Ramos, N., Fernández-Berrocal, P., \& Extremera, N. (2007). Perceived emotional intelligence facilitates cognitive-emotional processes of adaptation to an acute stressor. Cognition and Emotion, 21 , 758-772.

Rimé, B. (1995). Mental Rumination, Social Sharing, and the Recovery From Emotional Exposure. In J.W. Pennebaker (Eds.), Emotion, disclosure, and health (pp.271-291). Washington D.C.: American Psychological Association.

Rimé, B., Finkenauer, C., Luminet, O., Zech, E., \& Philippot, P. (1998). Social sharing of emotion: New evidence and new questions. In W. Stroebe, \& M. Hewstone (Eds.), European Review of Social Psychology (Vol. 9, pp. 145-198). Chichester: Wiley.

Rimé, B., Mesquita, B., Philippot, P., \& Boca, S. (1991). Beyond the emotional event: six studies on the social sharing of emotion. Cognition and Emotion, 5, 436-466.

Rimé, B., Noel, M.P., \& Philippot, P. (1991). Episode émotionnel, réminiscences mentales et réminiscences sociales. Cahiers Internationnaux de Psychologie Social, 11 , 93-104.

Rimé, B., Philippot, P., Boca, S., \& Mesquita, B. (1992). Long-lasting consequences of emotion : Social Sharing and Rumination. In W. Stroebe, \& M. Hewstone (Eds.), European Review of Social Psychology (Vol. 1, pp. 225-258). Chichester, England: Wiley.

Rude, S. S., \& McCarthy, C. T. (2003). Emotional functioning in depressed and depression vulnerable college students. Cognition and Emotion, 17, 799-806. 
Salovey, P., \& Mayer, J. D. (1990). Emotional intelligence. Imagination, Cognition and Personality, 9, 185-211.

Salovey, P., Mayer, J.D., Goldman, S.L., Turvey, C., \& Palfai, T.P. (1995). Emotional attention, clarity, and repair: Exploring emotional intelligence using the Trait Meta-Mood Scale. I J.W. Pennebaker (Ed.), Emotion, disclosure, and health (pp. 125-154). Washington: American Psychological Association.

Tugade, M.M. \& Fredrickson, B.L. (2007). Regulation of Positive Emotions: Emotion Regulation Strategies that Promote Resilience. Journal of Happiness Studies, 8, 31 1-333.

Tugade, M.M. \& Fredrickson, B.L. (2002). Positive emotions and emotional intelligence. In L. Feldman Barrett \& P. Salovey (Eds.), The Wisdom of Feelings, (pp. 319-340). Guilford: New York.

\section{About the authors}

Tiziana Lanciano is a research fellow in the Department of Psychology at the University of Bari, Italy. Her current research interests are emotion and memory, mental rumination, emotional intelligence, and latent-variable analysis.

Address for correspondence: t.lanciano@psico.uniba.it

Antonietta Curci is an associate professor in the Department of Psychology at the University of Bari, Italy. Her current research interests are emotion and memory, cognitive consequences of emotion, emotional intelligence, forensic psychology, and multivariate data analysis.

Edvige Zatton is a Psychology graduated at the University of Bari, Italy. Her current research interests are the psychological well-being in the child and in the adult, and the evaluation of interventions for psychological and education support in the schools. 